\title{
Synchronous and metachronous lung metastases in patients with colorectal cancer: A 20-year monocentric experience
}

\author{
HIROAKI NOZAWA $^{1}$, EIJI SUNAMI ${ }^{1}$, JUN NAKAJIMA ${ }^{2}$, HIROKAZU NAGAWA ${ }^{3}$ and JOJI KITAYAMA ${ }^{1}$ \\ Departments of ${ }^{1}$ Surgical Oncology, and ${ }^{2}$ Thoracic Surgery, The University of Tokyo, Tokyo 113-8655; \\ ${ }^{3}$ Japan Labour Health and Welfare Organization, Kawasaki 212-0013, Japan
}

Received September 1, 2011; Accepted November 18, 2011

DOI: 10.3892/etm.2011.443

\begin{abstract}
There is little information regarding the recent trend of synchronous and metachronous pulmonary metastases in patients with primary colorectal cancer. We investigated patients with sporadic colorectal cancer who underwent surgery in our department between 1990 and 2009. Clinicopathological parameters of primary cancer and lung metastases and survival time were retrospectively reviewed. Of the 2,286 patients included in this study, $64(2.8 \%)$ had synchronous lung metastases at the time of colorectal surgery. A total of 18 patients (28\%) received pulmonary metastasectomy for these lesions with curative intent. Out of 2,082 curatively operated cases, 212 (10.2\%) developed metachronous lung metastases. The frequency of synchronous and/or metachronous lung metastases detected in curative cases increased from $8.9 \%$ in the 1990 s to $11.9 \%$ in the 2000s ( $p=0.03$ ). Among predictive factors for metachronous lung metastases, the presence of distant organ metastases, i.e. initial stage IV, significantly increased over time. Notably, patients with unresectable metachronous lung metastases in the 2000s, characterized by smaller size, exhibited more favorable prognosis than in the 1990s ( $\mathrm{p}=0.003)$. Recent improvement of imaging modalities is considered to have facilitated the prompt diagnosis of lung metastases. Moreover, marked progress in multidisciplinary treatment has presumably achieved more favorable prognosis in an increasing number of patients with advanced colorectal cancer.
\end{abstract}

\section{Introduction}

Recent epidemiological studies have revealed that colorectal cancer (CRC) ranks among the leading malignancies in incidence in Western countries and Japan (1-3). It is well known that the lung is the most common extra-abdominal site of

Correspondence to: Dr Hiroaki Nozawa, Department of Surgical Oncology, The University of Tokyo, 7-3-1 Hongo, Bunkyo-ku, Tokyo 113-8655, Japan

E-mail: hiroanozawa-gi@umin.ac.jp

Key words: colorectal cancer, lung metastasis, stage IV, trend, survival metastasis from primary CRC (4). Approximately 10-20\% of surgical CRC cases develop lung metastases (5). In consideration of the vast prevalence of CRC and of the marked progress in diagnostic and treatment options, we anticipate more opportunities to detect lung metastases; however, there is still a paucity of detailed data on these issues in the literature.

In this study, we retrospectively investigated the features of metastasized lung tumors observed in over 2,000 surgical cases of sporadic CRC in a representative university hospital in Japan. Moreover, we assessed the risk factors for lung metastases in CRC patients and analyzed recent trends in frequency and survival.

\section{Patients and methods}

Patients. Patients with primary CRC who underwent surgery in our hospital between January 1990 and December 2009 were enrolled in this study. The subjects included those with i) inflammatory bowel disease-associated cancer, ii) synchronous multiple cancers of the colorectum, iii) cancer with simultaneous malignancies in other organs and iv) patients who had undergone palliative surgery for primary CRC. The exclusion criteria were i) cancer arising in patients diagnosed with familial adenomatous polyposis or Lynch syndrome, ii) anal fistula-associated cancer, iii) locally recurrent tumor alone in previously resected $\mathrm{CRC}$, and iv) metastasized tumors in the colorectum originating from other primary organs. For analyses of metachronous lung tumors, only patients who had undergone curative surgery (R0) for primary CRC were assembled. Written, informed consent was obtained from each patient participating in this study.

Synchronous tumors. Synchronous tumors were defined as those cases in which lesions were observed prior to or within 3 months after the surgery for CRC, and were otherwise judged as metachronous tumors. There is no definite consensus regarding synchronous and metachronous metastases; however, we set this cut-off time-point, since the first opportunity for follow-up image study occurred at 3 postoperative months, as mentioned below, in our institution. Patients with lower rectal cancer were often treated with preoperative chemoradiation therapy, once there was no clear distant metastasis. Certain CRC patients with massive liver metastases received systemic chemotherapy prior to surgery. Pulmonary tumors revealed during such neoadjuvant therapies, for example, were defined as synchronous tumors. 
Patient examination. In our hospital, patients were routinely examined by chest radiography, abdomino-pelvic and chest CT scans with contrast in order to identify potential liver, lung, lymph node, or other organ metastases prior to CRC surgery. Following surgery, patients were surveyed primarily by CT scans and chest X-ray, first within 3-6 months, then every 6 months for 2 years, and thereafter every 12 months. Other image studies such as magnetic resonance imaging and positron emission tomography were additionally performed at the doctors' discretion.

Clinical data. Clinical data such as gender, age, ECOG performance status (PS), family history of CRC, i.e. CRC cases in first-degree relative(s), and smoking habits, histopathological parameters of primary CRC, parameters of lung metastases such as the number, tumor laterality and size at diagnosis, and survival time were obtained from medical records. The pathological description of CRC was essentially based on the TNM classification, 7th edition (6). The study was conducted with the approval of the ethics committee of our hospital.

Statistical analysis. Comparisons between groups were performed using the Student's t-test, Welch's t-test, Fisher's exact test or the Chi-square test, applying Yates' correction when needed. Multivariate analysis by logistic regression was used to identify independent predictors. The survival curve was estimated using the Kaplan-Meier method and analyzed using the log-rank test. A p-value of $<0.05$ was considered indicative of statistical significance.

\section{Results}

Profile of surgical CRC patients. A total of 2,286 patients (1,448 males and 838 females; age, 22-94 years; average, 64.2 years) with primary CRC were eligible for analysis of synchronous metastases in this study. Other clinical and pathological data are shown in Table I. Among them, 2,082 patients underwent curative surgery and were subjected to analyses of metachronous lung metastases. Non-curative CRC cases showed markedly higher percentages of poor PS (PS $\geq 1,32 \%$ ), undifferentiated histology $(16 \%)$, larger $\mathrm{T}(\mathrm{T} 4,11 \%)$ and $\mathrm{N}$ numbers $(\mathrm{N}+, 59 \%)$ and M1/UICC stage IV (94\%), and larger tumor diameter (mean, $57.4 \mathrm{~mm}$ ) than curative cases (PS $\geq 1,9 \%$; undifferentiated histology, 6\%; T4, 4\%; and N+, 34\%; M1, 8\% and mean diameter, $42.1 \mathrm{~mm}$, respectively). In addition, female patients, a right-sided colon, and a positive family history of $\mathrm{CRC}$ were more frequent in non-curative than in curative cases.

Frequencies of synchronous and metachronous lung metastases in CRC patients between 1990-1999 and 2000-2009. Table II summarizes the frequencies of metastasized lung tumors observed in CRC patients. Lung metastases were identified in $64(2.8 \%)$ of 2,286 surgical cases at the time of colorectal surgery. Among them, 18 patients (28\%) underwent curative resection for both primary and metastasized tumors. Of the 2,082 curatively operated CRC cases, 212 (10.2\%) developed metastasized tumors in the lung metachronously.

To identify the time trends of lung tumors in CRC, we divided the CRC patients who had undergone curative resection into 2 calendar periods, 1990-1999 (first decade) and
2000-2009 (second decade), according to the time of colorectal surgery. The mean follow-up periods were 2,733 $\pm 2,042$ and $1,550 \pm 951$ days, respectively $(\mathrm{p}<0.0001)$. The frequency of synchronous lung metastases $(3.7 \%)$ was significantly higher in 2000-2009 than in 1990-1999 (1.4\%, $\mathrm{p}=0.001)$. The percentage of CRC patients whose synchronous lung metastases were curatively resected tended to be higher in 2000-2009 than in 1990-1999 (1.1 vs. 0.5\%), although the difference was not statistically significant $(\mathrm{p}=0.19)$. The frequency of metachronous lung metastases (11.3\%) in 2000-2009, despite a shorter duration of follow-up, was significantly higher than in $1990-1999$ (8.5\%, $\mathrm{p}=0.04)$. In these patients, the resection rate was $51 \%$ for the first decade and $38 \%$ for the second. The total frequency of lung metastases in CRC patients in their lifetime was significantly higher in the second decade (11.9\%) than in the first $(8.9 \%, \mathrm{p}=0.03)$.

Factors affecting the appearance of lung metastases in CRC patients undergoing curative surgery. To identify risk factors related to the appearance of lung metastases, clinicopathological parameters of CRC cases with metachronous lung metastases were compared with the other cases. Univariate analysis revealed that age, location, size and depth of primary $\mathrm{CRC}$, regional lymph node metastasis, distant organ metastasis and a family history of CRC were correlated with lung metastases (Table III). These parameters were further subjected to multivariate logistic regression analysis. The results revealed that a tumor in the rectum [odds ratio $(O R)=2.450$ ] and the presence of lymph node metastasis $(\mathrm{OR}=2.967)$ and distant organ metastases $(\mathrm{OR}=4.185)$ were independent predictive factors for metachronous lung tumors in CRC $(\mathrm{p}<0.0001$, Table IV).

Comparison of clinicopathological parameters of CRC patients between 1990-1999 and 2000-2009. To investigate the causes for the increased lung metastases in CRC patients, the profiles of curative CRC cases were compared between 1990-1999 and 2000-2009. As shown in Table V, gender and ECOG PS distributions were similar between the groups. Surgery was performed on older patients in 2000-2009 than in 1990-1999 (average ages: 65.5 and 62.2 years, respectively; $\mathrm{p}<0.0001)$. The size of primary CRC was smaller in the second period (mean diameter: $40.9 \mathrm{~mm}$ ) than in the first $(43.9 \mathrm{~mm}$, $\mathrm{p}=0.005$ ). Throughout the 2 decades, $>90 \%$ of histology was differentiated adenocarcinoma. The rectum was the most common location (42\%) in both decades, although there was a difference in the locations of primary colon cancers between the 2 time periods. There were no significant changes in the distribution of pathological $\mathrm{T}$ and $\mathrm{N}$ numbers; however, more stage IV CRC patients (M1) underwent curative surgery in 2000-2009 than in 1990-1999 (9\% vs. 6\%). In 1990-1999, 5\% of the patients had first-degree relative(s) with CRC, whereas 9\% had a positive family history of CRC in 2000-2009 $(\mathrm{p}=0.01)$. There was no intergroup difference in the percentage of current or ex-smokers (54\% and 56\% for 1990-1999 and 2000-2009, respectively, $\mathrm{p}=0.76$ ).

Survival of CRC patients according to the onset of lung metastases and time period. In synchronous lung metastases, the 5-year survival rate of patients who underwent pulmonary 
Table I. Clinicopathological profile of CRC patients.

\begin{tabular}{|c|c|c|c|c|}
\hline Variable & $\begin{array}{c}\text { All } \\
(\mathrm{n}=2,286)(\%)\end{array}$ & $\begin{array}{c}\text { Curative } \\
(\mathrm{n}=2,082)(\%)\end{array}$ & $\begin{array}{l}\text { Non-curative } \\
(n=204)(\%)\end{array}$ & P-value \\
\hline \multicolumn{5}{|l|}{ Gender } \\
\hline Male & $1,448(63)$ & $1,337(64)$ & $111(54)$ & \multirow[t]{2}{*}{0.006} \\
\hline Female & $838(37)$ & 745 (36) & $93(46)$ & \\
\hline \multicolumn{5}{|l|}{ Age (years) } \\
\hline Mean \pm SD & $64.2 \pm 11.2$ & $64.2 \pm 11.2$ & $64.2 \pm 11.3$ & 0.99 \\
\hline \multicolumn{5}{|l|}{$\begin{array}{l}\text { ECOG performance } \\
\text { status }\end{array}$} \\
\hline 0 & $2,031(88)$ & $1,894(91)$ & 137 (67) & \multirow[t]{6}{*}{$<0.0001$} \\
\hline 1 & $181(8)$ & $143(7)$ & 38 (19) & \\
\hline 2 & $48(2)$ & $31(2)$ & $17(8)$ & \\
\hline 3 & $13(1)$ & $7(0)$ & $6(3)$ & \\
\hline 4 & $11(1)$ & $7(0)$ & $4(2)$ & \\
\hline Unknown & $2(0)$ & $0(0)$ & $2(1)$ & \\
\hline \multicolumn{5}{|l|}{$\begin{array}{l}\text { Location of primary } \\
\text { cancer }^{\mathrm{a}}\end{array}$} \\
\hline Right-sided colon & $551(24)$ & $489(23)$ & $62(30)$ & \multirow[t]{3}{*}{0.008} \\
\hline Left-sided colon & 769 (34) & $719(35)$ & $50(25)$ & \\
\hline Rectum & $966(42)$ & $874(42)$ & $92(45)$ & \\
\hline \multicolumn{5}{|l|}{ Histological type } \\
\hline Differentiated & $2,101(92)$ & $1,944(93)$ & $157(76)$ & \multirow[t]{3}{*}{$<0.0001$} \\
\hline Undifferentiated & $161(7)$ & $129(6)$ & $32(16)$ & \\
\hline Unknown & $26(1)$ & $9(1)$ & $17(8)$ & \\
\hline \multicolumn{5}{|l|}{$\begin{array}{l}\text { Maximum tumor } \\
\text { diameter }(\mathrm{mm})^{\mathrm{b}}\end{array}$} \\
\hline Mean \pm SD & $43.1 \pm 23.7$ & $42.1 \pm 23.4$ & $57.4 \pm 23.6$ & $<0.0001$ \\
\hline \multicolumn{5}{|l|}{ Depth } \\
\hline $\mathrm{T} 0^{\mathrm{c}}$ & $89(4)$ & $87(4)$ & $2(1)$ & \multirow[t]{6}{*}{$<0.0001$} \\
\hline $\mathrm{T} 1$ & $316(14)$ & $316(15)$ & $0(0)$ & \\
\hline $\mathrm{T} 2$ & $334(15)$ & $329(16)$ & $5(2)$ & \\
\hline $\mathrm{T} 3$ & 1,397 (61) & $1,274(61)$ & $123(60)$ & \\
\hline $\mathrm{T} 4$ & $99(4)$ & $76(4)$ & $23(11)$ & \\
\hline Unknown & $51(2)$ & $2(0)$ & $49(24)$ & \\
\hline \multicolumn{5}{|c|}{$\begin{array}{l}\text { Regional lymph node } \\
\text { metastasis }\end{array}$} \\
\hline N0 & $1,353(59)$ & $1,325(64)$ & $28(13)$ & \multirow[t]{5}{*}{$<0.0001$} \\
\hline N1 & $567(25)$ & 507 (24) & $60(29)$ & \\
\hline $\mathrm{N} 2$ & $215(9)$ & $176(8)$ & 39 (19) & \\
\hline N3 & $59(2)$ & $37(2)$ & $22(11)$ & \\
\hline Unknown & $92(4)$ & $37(2)$ & $55(27)$ & \\
\hline \multicolumn{5}{|l|}{ Distant metastasis } \\
\hline M0 & $1,922(84)$ & $1,915(92)$ & $7(3)$ & \multirow[t]{3}{*}{$<0.0001$} \\
\hline M1 & 358 (16) & $167(8)$ & $191(94)$ & \\
\hline Unknown & $6(0)$ & $0(0)$ & $6(3)$ & \\
\hline \multicolumn{5}{|l|}{ Initial UICC stage } \\
\hline $0^{c}$ & $86(4)$ & $85(4)$ & $1(0)$ & \multirow[t]{6}{*}{$<0.0001$} \\
\hline I & $542(24)$ & $542(26)$ & $0(0)$ & \\
\hline II & $689(30)$ & $689(33)$ & $0(0)$ & \\
\hline III & $600(26)$ & $599(29)$ & $1(0)$ & \\
\hline IV & $358(16)$ & $167(8)$ & $191(94)$ & \\
\hline Unknown & $11(0)$ & $0(0)$ & $11(6)$ & \\
\hline
\end{tabular}


Table I. Continued.

\begin{tabular}{lccc}
\hline Variable & $\begin{array}{c}\text { All } \\
(\mathrm{n}=2,286)(\%)\end{array}$ & $\begin{array}{c}\text { Curative } \\
(\mathrm{n}=2,082)(\%)\end{array}$ & $\begin{array}{c}\text { Non-curative } \\
(\mathrm{n}=204)(\%)\end{array}$ \\
\hline $\begin{array}{l}\text { Family history of } \\
\text { primary CRC }\end{array}$ & & & P-value \\
Absent & $2,007(88)$ & $1,920(92)$ & $87(43)$ \\
Present & $271(12)$ & $154(7)$ & $0(0)$ \\
Unknown & $8(0)$ & $8(0)$ & $97(48)$ \\
Smoking habit & $1,021(45)$ & $9,243(45)$ & $107(52)$ \\
Never smoked & $1,258(55)$ & $1,152(55)$ & 0.40 \\
Current or & $7(0)$ & $7(0)$ & 0001 \\
ex-smoker & & & $070)$ \\
Unknown & & & $(0)$ \\
\hline
\end{tabular}

${ }^{a}$ Location of more advanced case was counted in cases of multiple CRCs. ${ }^{b}$ Excludes cases in which data were not available. ${ }^{c}$ Includes cases of CRC after preoperative chemoradiation for primary cancer. CRC, colorectal cancer.

Table II. Frequencies of lung metastases in (A) all surgical CRC cases and (B) the curatively resected cases according to the time period.

A, All cases.

\begin{tabular}{lccc}
\hline & \multicolumn{3}{c}{ Cases with lung metastasis } \\
\cline { 2 - 4 } & $\begin{array}{c}\text { Total } \\
(\mathrm{n}=2,286)(\%)\end{array}$ & $\begin{array}{c}1990-1999 \\
(\mathrm{n}=919)(\%)\end{array}$ & $\begin{array}{c}2000-2009 \\
(\mathrm{n}=1,367)(\%)\end{array}$ \\
\hline Synchronous & $64(2.8)$ & $13(1.4)$ & $51(3.7)$ \\
\hline
\end{tabular}

B, Curative cases.

\begin{tabular}{lccc}
\hline & \multicolumn{3}{c}{ Cases with lung metastasis } \\
\cline { 2 - 4 } & $\begin{array}{c}\text { Total } \\
(\mathrm{n}=2,082)(\%)\end{array}$ & $\begin{array}{c}1990-1999 \\
(\mathrm{n}=835)(\%)\end{array}$ & $\begin{array}{c}2000-2009 \\
(\mathrm{n}=1,247)(\%)\end{array}$ \\
\hline Synchronous & $18(0.9)$ & $4(0.5)$ & $14(1.1)$ \\
Metachronous & $212(10.2)$ & $71(8.5)$ & $141(11.3)$ \\
Non-resected/Resected & $123 / 89$ & $35 / 36$ & $88 / 53$ \\
Total $^{\mathrm{a}}$ & $223(10.7)$ & $74(8.9)$ & $149(11.9)$ \\
\hline
\end{tabular}

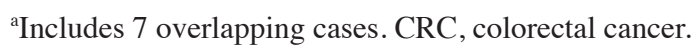

metastasectomy $(n=18)$ was $65 \%$. There was no surgery-related mortality. On the contrary, patients who had not undergone pulmonary metastasectomy $(n=46)$ succumbed to the disease in less than 4.2 years $(p=0.0003$, data not shown).

With regard to metachronous lung metastases, the 5-year survival rate following diagnosis of lung metastases was $60 \%$ for cases of metastasectomy $(n=89)$, whereas it was only $15 \%$ for other palliative cases $(n=123)(p<0.0001$, data not shown). In order to reveal any chronological changes in survival of these patients, they were further subdivided according to the calendar period. The survival curves of patients who received lung resection for metastasized tumors were similar between the 2 time periods. Their 5-year survival rate was $58 \%$ for the first decade, and $63 \%$ for the second ( $p=0.85$, Fig. $1 \mathrm{~A}$ ). Notably, patients without metastasectomy survived significantly longer in 2000-2009 than in 1990-1999 ( $\mathrm{p}=0.003)$. Only $19 \%$ survived 2 years in the 1990-1999 group, whereas $48 \%$ survived for the same duration in 2000-2009, due to non-surgical treatment for lung metastases (Fig. 1B).

Features of non-resected metachronous lung metastases between 1990-1999 and 2000-2009. Finally, we compared 
Table III. Clinicopathological factors of the curatively operated CRC patients with and without metachronous lung metastases.

\begin{tabular}{|c|c|c|c|}
\hline Parameter & $\begin{array}{l}\text { Metastasis }(-) \\
\quad(n=1,870)\end{array}$ & $\begin{array}{c}\text { Metastasis }(+) \\
\quad(n=212)\end{array}$ & P-value \\
\hline $\begin{array}{l}\text { Gender } \\
\text { (male, female) }\end{array}$ & 1,210:660 & $127: 85$ & 0.17 \\
\hline $\begin{array}{l}\text { Age } \\
(\text { years; mean } \pm \text { SD) }\end{array}$ & $64.4 \pm 11.2$ & $62.2 \pm 10.2$ & 0.008 \\
\hline $\begin{array}{l}\text { ECOG } \\
\text { performance status } \\
(0-1,2-4)\end{array}$ & $1,825: 45$ & 211:1 & 0.12 \\
\hline $\begin{array}{l}\text { Location of } \\
\text { primary cancer } \\
\text { (colon, rectum) }\end{array}$ & $1,128: 742$ & $80: 132$ & $<0.0001$ \\
\hline $\begin{array}{l}\text { Histological type } \mathrm{e}^{\mathrm{a}} \\
\text { (diff., undiff.) }\end{array}$ & $1,744: 117$ & 200:12 & 0.84 \\
\hline $\begin{array}{l}\text { Maximum tumor } \\
\text { diameter } \\
(\mathrm{mm} ; \text { mean } \pm \mathrm{SD})\end{array}$ & $41.4 \pm 23.6$ & $48.1 \pm 21.0$ & $<0.0001$ \\
\hline $\begin{array}{l}\text { Depth } \\
\text { (T0-2, T3-4) }\end{array}$ & $706: 1,162$ & $26: 186$ & $<0.0001$ \\
\hline $\begin{array}{l}\text { Regional lymph } \\
\text { node metastasis } \\
(-,+)\end{array}$ & $1,250: 584$ & $75: 136$ & $<0.0001$ \\
\hline $\begin{array}{l}\text { Distant metastasis } \\
(\mathrm{M} 0, \mathrm{M} 1)\end{array}$ & $1,764: 106$ & 151:61 & $<0.0001$ \\
\hline $\begin{array}{l}\text { Family history } \\
\text { of CRC } \\
(-,+)\end{array}$ & $1,738: 124$ & $182: 30$ & $<0.0001$ \\
\hline $\begin{array}{l}\text { Smoking habit } \\
(-,+)\end{array}$ & $826: 1,037$ & $97: 115$ & 0.69 \\
\hline
\end{tabular}

Diff., differentiated; undiff., undifferentiated. ${ }^{\text {aExcludes cases in which }}$ data were not available. CRC, colorectal cancer.

clinicopathological features of metachronous lung metastases that were not resected between 1990-1999 and 2000-2009. As shown in Table VI, the frequencies of multiple, bilateral metastases, elevated carcinoembryonic antigen (CEA) levels in the serum and the presence of other organ metastases at the time of diagnosis did not vary significantly between the time periods. Disease-free interval (DFI) tended to be shorter in the 2000s, but the difference did not reach statistical significance. Only the diameter of the largest lung deposit was significantly smaller in patients in the $2000 \mathrm{~s}$ (mean, $9.8 \pm 7.9 \mathrm{~mm}$ ) than in the 1990s (mean, $17.7 \pm 15.0 \mathrm{~mm} ; \mathrm{p}=0.01$ ).

\section{Discussion}

Recent progress in multimodal treatments for CRC has achieved a more favorable prognosis. An increasing number of advanced CRC patients, even those with distant metastases, have the opportunity to undergo curative surgery following state-of-the-art neoadjuvant chemotherapy and radiation
Table IV. Multivariate logistic regression analysis on parameters associated with metachronous lung metastases

\begin{tabular}{|c|c|c|c|c|}
\hline Parameter & $\begin{array}{c}\text { Chi-square } \\
\text { value }\end{array}$ & OR & $95 \% \mathrm{CI}$ & P-value \\
\hline $\begin{array}{l}\text { Age } \\
(<65 \text { vs. } \\
\geq 65 \text { years })\end{array}$ & 0.890 & 1.163 & $0.849-1.593$ & 0.35 \\
\hline $\begin{array}{l}\text { Location of } \\
\text { primary cancer } \\
\text { (rectum vs. } \\
\text { colon) }\end{array}$ & 31.459 & 2.450 & $1.791-3.351$ & $<0.0001$ \\
\hline $\begin{array}{l}\text { Maximum tumor } \\
\text { diameter } \\
(>40 \mathrm{vs} . \leq 40 \mathrm{~mm})\end{array}$ & 0.852 & 0.862 & $0.629-1.182$ & 0.36 \\
\hline $\begin{array}{l}\text { Depth } \\
\text { (T3-4 vs. T0-2) }\end{array}$ & 0.771 & 1.168 & $0.825-1.654$ & 0.38 \\
\hline $\begin{array}{l}\text { Regional lymph } \\
\text { node metastasis } \\
\text { (present vs. } \\
\text { absent) }\end{array}$ & 44.182 & 2.967 & $2.155-4.098$ & $<0.0001$ \\
\hline $\begin{array}{l}\text { Distant metastasis } \\
\text { (M1 vs. M0) }\end{array}$ & 50.860 & 4.185 & $2.824-6.202$ & $<0.0001$ \\
\hline $\begin{array}{l}\text { Family history } \\
\text { of CRC } \\
\text { (present vs. } \\
\text { absent) }\end{array}$ & 1.786 & 1.350 & $0.869-2.098$ & 0.18 \\
\hline
\end{tabular}

OR, odds ratio, CI, confidence interval. CRC, colorectal cancer.

therapy, and consequently are likely to survive for longer than they previously would have (7). Given these trends, we envisioned that doctors would encounter lung metastases more frequently in the postoperative follow-up. Data collected over a period of 20 years from our institution have clearly demonstrated that the overall incidence of lung metastases in curative CRC cases has risen from $8.9 \%$ in $1990-1999$ to $11.9 \%$ in 2000-2009 (Table II). Due to a shorter follow-up duration, the true frequency in the second decade may actually be higher.

Our observation that lung metastases have increased over time in CRC patients was partially consitent with a study by Mitry et al based on their experience between 1976 and 2005 (8). They revealed that the risk of synchronous metastases in the lung was 3.77 times higher in 1996-2005 than in 1976-1985. However, we also found a significant increase in metachronous lung tumors in 2000-2009 as compared to 1990-1999, which differed from their results. The increasing incidence of synchronous metastases may be attributable to the improvement of diagnostic tools, such as CT scans (9); however, the high detection rate of metachronous lung tumors is not explained simply by the improved quality of imaging modalities, since these malignant lesions will grow and be detected eventually. In order to investigate which other factors caused lung deposits to be detected more often in 2000-2009 than in 1990-1999, we adopted two approaches. Firstly, we aimed to identify parameters associated with the appearance of lung tumors by 
Table V. Clinicopathological profile of the curatively resected CRC patients in the periods 1990-1999 and 2000-2009.

\begin{tabular}{lcc}
\hline & \multicolumn{2}{c}{ Period } \\
\cline { 2 - 3 } Variable & $\begin{array}{c}1990-1999 \\
(\mathrm{n}=835)(\%)\end{array} \quad(\mathrm{n}=1,247)(\%)$ & \\
\hline
\end{tabular}

\section{Gender}

Male

Female

$555(66)$
$280(34)$

$782(63)$

0.08

Age (years)

Mean \pm SD

$62.2 \pm 11.0$

$65.5 \pm 11.0$

$<0.0001$

ECOG performance

status

0

1

2

3

4

Location of

primary cancer ${ }^{\mathrm{a}}$

Right-sided colon
Left-sided colon
Rectum
Histological type
Differentiated
Undifferentiated
Unknown

$164(20)$

$319(38)$

$352(42)$

$1,129(91)$
$89(7)$
$19(2)$
$5(0)$
$5(0)$

0.98

54 (7)

$12(1)$

$2(0)$

$2(0)$

$5(0)$

$\begin{array}{ccc}771(92) & 1,173(94) & 0.50 \\ 55(7) & 74(6) & \\ 9(1) & 0(0) & \end{array}$

Maximum tumor diameter $(\mathrm{mm})^{\mathrm{b}}$

Mean \pm SD
Depth
T0
T1
T2
T3
T4

Regional lymph node metastasis

N0
N1
N3

Distant metastasis

M0
M1

0.0008

0.005

104 (12)

Initial UICC stage

I

37 (4)

$194(23)$

$300(36)$

$255(31)$

49 (6)
48 (4)

389 (31)

344 (28)

118 (9)
Table V. Continued.

\begin{tabular}{|c|c|c|c|}
\hline \multirow[b]{2}{*}{ Variable } & \multicolumn{2}{|c|}{ Period } & \multirow[b]{2}{*}{ P-value } \\
\hline & $\begin{array}{c}1990-1999 \\
(\mathrm{n}=835)(\%)\end{array}$ & $\begin{array}{c}2000-2009 \\
(\mathrm{n}=1,247)(\%)\end{array}$ & \\
\hline \multicolumn{4}{|l|}{$\begin{array}{l}\text { Family history } \\
\text { of CRC }\end{array}$} \\
\hline Absent & $782(94)$ & $1,135(91)$ & 0.01 \\
\hline Present & $48(5)$ & $109(9)$ & \\
\hline Unknown & $5(1)$ & $4(0)$ & \\
\hline \multicolumn{4}{|l|}{ Smoking habit } \\
\hline Never smoked & $373(45)$ & $550(44)$ & 0.73 \\
\hline $\begin{array}{l}\text { Current or } \\
\text { ex-smoker }\end{array}$ & 457 (54) & $695(56)$ & \\
\hline Unknown & $5(1)$ & $3(0)$ & \\
\hline \multicolumn{4}{|c|}{$\begin{array}{l}\text { aLocation of more advanced case was counted in cases of multiple } \\
\text { CRC. }{ }^{b} \text { Excludes cases in which data were not available. 'Includes } \\
\text { cases of CRC after preoperative chemoradiation for primary cancer. } \\
\text { CRC, colorectal cancer. }\end{array}$} \\
\hline
\end{tabular}

univariate and multivariate analyses, and secondly, we examined those parameters that changed over time. Synchronous lung tumors were excluded in the first approach since the presence of synchronous lung metastases itself is defined as M1 as an explanatory variable. The analyses underscored parameters such as rectal cancer and the presence of lymph node and distant organ metastases at CRC surgery as predictive factors for late lung metastases (Table IV). The second approach elucidated a different set of parameters; the 2000-2009 cohort included older patients, smaller CRC tumors, more frequent location in the right-sided colon, and higher percentages of distant metastases and a positive family history of CRC compared to the 1990-1999 cohort (Table V); therefore, the presence of distant metastases was the only factor commonly indicated by these comparison analyses. The number of stage IV CRC patients was 1.6-fold higher in 2000-2009 than in 1990-1999 (Table V). It is well accepted that hematogenous metastases from CRC generally occur first in the liver, due to venous drainage via the portal system, and then later appear systemically, including in the lung. Consistent with this hypothesis, our results indicated that extra-pulmonary [such as hepatic (representing $74 \%$ in our study)] metastases were a risk factor for sequential lung metastases.

Surgical removal was beneficial to patients with lung metastases in our series, as reported previously (10), although there was a selection bias in the indications for metastasectomy in this retrospective study. As shown in Fig. 1A, the overall survival of CRC patients following metachronous pulmonary metastasectomy was largely in concordance with the 5-year survival rate of $24-68 \%$ reported previously (10-12). It is noteworthy that $\mathrm{CRC}$ patients with inoperable lung metastases exhibited markedly more favorable prognosis in the second decade compared to the first decade (Fig. 1B). Few studies have exclusively investigated the trend in the prognosis of unresect- 
A

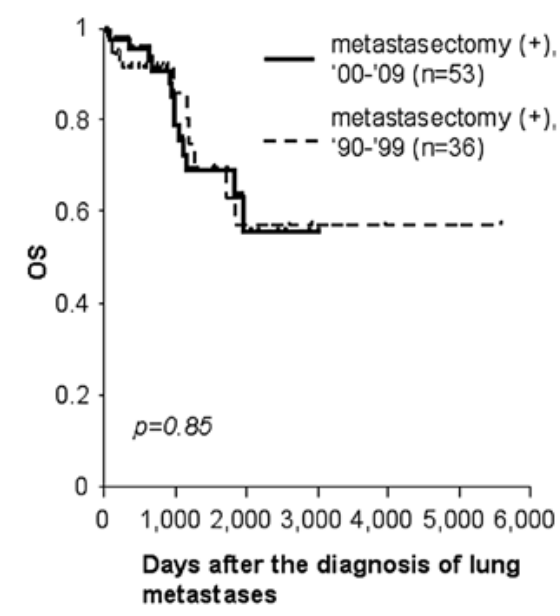

B

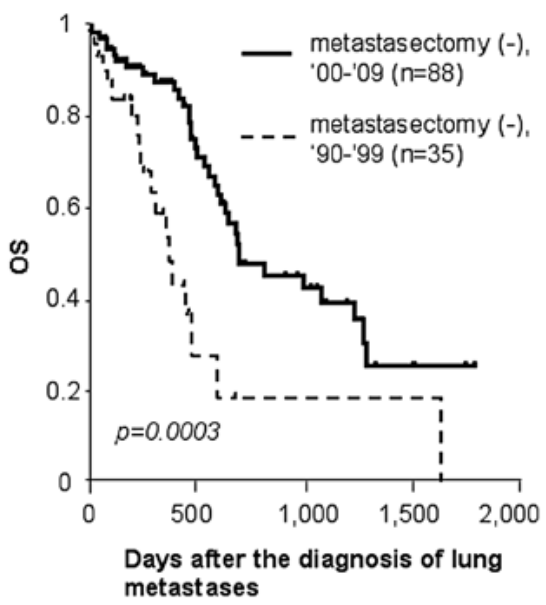

Figure 1. Subgroup survival analysis of patients with metachronous lung metastases who underwent curative colorectal surgery. (A) Survival of patients who underwent pulmonary metastasectomy in 1990-1999 and 2000-2009. (B) Survival of patients who did not undergo pulmonary metastasectomy in 1990-1999 and 2000-2009. OS, overall survival. Bold lines indicate survival curves of cases in 2000-2009, and dotted lines those in 1990-1999.

able lung metastases from CRC. A number of investigators have been seeking prognostic factors for the postoperative survival of patients with lung metastases using univariate and multivariate evaluation. When summarizing the results, incomplete removal of tumors, short DFI, multiple metastases and elevated CEA levels in the serum were preferentially documented as significant predictors of poor prognosis following pulmonary metastasectomy (11-17). With the exception of the first technical factor, these indices are considered to indicate the more aggressive phenotype of metastatic CRC cells. Provided that the same is universally true of lung metastasis-positive CRC irrespective of pulmonary resection, these markers would be benefit the evaluation of any chronological changes in the grade of malignancy of non-resected lung metastases. In this context, we compared clinicopathological factors of unresected metachronous lung metastases including DFI, the percentages of multiple metastases and CEA elevation between 1990-1999 and 2000-2009, but there existed no significant differences in the
Table VI. Characteristics of non-resected metachronous lung metastases according to the time period.

\begin{tabular}{lccc}
\hline Variable & $\begin{array}{c}1990-1999 \\
(\mathrm{n}=35)\end{array}$ & $\begin{array}{c}2000-2009 \\
(\mathrm{n}=88)\end{array}$ & P-value \\
\hline $\begin{array}{l}\text { DFI (days) } \\
\text { (mean } \pm \text { SD) }\end{array}$ & $776 \pm 676$ & $533 \pm 465$ & 0.06 \\
$\begin{array}{l}\text { Number } \\
\text { (single, multiple) }\end{array}$ & $7: 26$ & $20: 66$ & 1.00 \\
$\begin{array}{l}\text { Laterality } \\
\text { (ipsilateral, bilateral) }\end{array}$ & $8: 25$ & $35: 53$ & 0.17 \\
$\begin{array}{l}\text { Maximum size (mm) } \\
\text { (mean } \pm \text { SD) }\end{array}$ & $17.7 \pm 15.0$ & $9.8 \pm 7.9$ & 0.01 \\
$\begin{array}{l}\text { Serum CEA level } \\
\text { (normal, elevated })\end{array}$ & $5: 26$ & $23: 60$ & 0.30 \\
$\begin{array}{l}\text { Other organ metastases } \\
\text { (absent, present) }\end{array}$ & $13: 22$ & $19: 69$ & 0.08 \\
\hline
\end{tabular}

DFI, disease free interval; CEA, carcinoembryonic antigen. ${ }^{a}$ Excludes cases in which data were not available; $>5 \mathrm{ng} / \mathrm{ml}$.

majority of variables. Exceptionally, lung deposits of smaller size were detected in 2000-2009 as compared to 1990-1999 (Table VI). The majority of previous studies uniformly failed to define the size of the largest metastasis as a predictive factor for survival of CRC patients with pulmonary metastasectomy $(11,12,14-17)$. Taken together, we envision that earlier detection of lung deposits as well as marked progress in multidisciplinary treatment, for example, effective chemotherapeutic regimens in combination with monoclonal antibodies (7), has resulted in prolonged survival in patients with unresectable lung metastases.

In conclusion, an increasing number of stage IV CRC patients underwent curative resection between 2000 and 2009 in our hospital, which resulted in a higher incidence of lung metastases detected in the follow-up period. Diagnostic and non-surgical therapeutic progress has been of particular benefit to $\mathrm{CRC}$ patients with inoperable lung metastases; therefore, it will be of greater importance to make accurate diagnosis of, and develop appropriate treatment strategies for, lung tumors observed in CRC cases.

\section{Acknowledgements}

This study was supported by the Ministry of Education, Culture, Sports, Science and Technology of Japan, and the Ministry of Health, Labor and Welfare of Japan.

\section{References}

1. Ferlay J, Parkin DM and Steliarova-Foucher E: Estimates of cancer incidence and mortality in Europe in 2008. Eur J Cancer 46: 765-781, 2010

2. Jemal A, Siegel R, Xu J and Ward E: Cancer statistics, 2010. CA Cancer J Clin 60: 277-300, 2010. 
3. Matsuda T, Marugame T, Kamo K, et al: Cancer incidence and incidence rates in Japan in 2005: based on data from 12 populationbased cancer registries in the Monitoring of Cancer Incidence in Japan (MCIJ) project. Jpn J Clin Oncol 41: 139-147, 2011.

4. Galandiuk S, Wieand HS, Moertel CG, et al: Patterns of recurrence after curative resection of carcinoma of the colon and rectum. Surg Gynecol Obstet 174: 27-32, 1992.

5. Penna $\mathrm{C}$ and Nordlinger B: Colorectal metastases (liver and lung). Surg Clin N Am 82: 1075-1090, 2002.

6. Sobin LH, Gospodarowicz MK and Wittekind C (eds): TNM Classification of Malignant Tumors. 7th edition. John Wiley \& Sons Inc., New Jersey, 2009.

7. Cunningham D, Atkin W, Lenz HJ, et al: Colorectal cancer. Lancet 375: 1030-1047, 2010

8. Mitry E, Guiu B, Cosconea S, Jooste V, Faivre J and Bouvier AM: Epidemiology, management and prognosis of colorectal cancer with lung metastases: a 30-year population-based study. Gut 59: $1383-1388,2010$

9. Kirke R, Rajesh A, Verma R and BanKart MJ: Rectal cancer: incidence of pulmonary metastases on thoracic CT and correlation with T staging. J Comput Assist Tomogr 31: 569-571, 2007.

10. Pfannschmidt J, Dienemann H and Hoffmann H: Surgical resection of pulmonary metastases from colorectal cancer: a systematic review of published series. Ann Thorac Surg 84: 324-338, 2007
11. Onaitis MW, Petersen RP, Haney JC, et al: Prognostic factors for recurrence after pulmonary resection of colorectal cancer metastases. Ann Thorac Surg 87: 1684-1689, 2009.

12. Watanabe K, Nagai K, Kobayashi A, Sugito M and Saito N: Factors influencing survival after complete resection of pulmonary metastases from colorectal cancer. Br J Surg 96: 1058-1065, 2009

13. Rena O, Casadio C, Viano F, et al: Pulmonary resection for metastases from colorectal cancer: factors influencing prognosis. Twenty-year experience. Eur J Cardiothorac Surg 21: 906-912, 2002.

14. Watanabe I, Arai T, Ono M, et al: Prognostic factors in resection of pulmonary metastasis from colorectal cancer. Br J Surg 90: 1436-1440, 2003.

15. Iizasa T, Suzuki M, Yoshida S, et al: Prediction of prognosis and surgical indications for pulmonary metastasectomy from colorectal cancer. Ann Thorac Surg 82: 254-260, 2006.

16. Yedibela S, Klein P, Feuchter K, et al: Surgical management of pulmonary metastases from colorectal cancer in 153 patients. Ann Surg Oncol 13: 1538-1544, 2006.

17. Rama N, Monteiro A, Bernardo JE, Eugénio L and Antunes MJ: Lung metastases from colorectal cancer: surgical resection and prognostic factors. Eur J Cardiothorac Surg 35: 444-449, 2009. 